\title{
CONSTRUÇÃO E RECONSTRUÇÃO DE UM SISTEMA HIPERMÍDIA SOBRE ANTICORPOS MONOCLONAIS COM BASE NA ESTRUTURA COGNITIVA DO ESPECIALISTA DE CONTEÚDO*
}

\section{Building and rebuilding of a hipermidia system based on the teaching/specialist content's cognitive structure: a case study on monoclonal antibodies system}

\author{
Miriam Struchiner ${ }^{1}$ \\ Regina Maria Vieira Ricciardi ${ }^{2}$ \\ Taís Rabetti Gianella ${ }^{3}$
}

\begin{abstract}
Resumo: Relata-se o desenvolvimento do sistema hipermídia Anticorpos Monoclonais, com desenho baseado no conhecimento estrutural de um especialista de conteúdo. A primeira versão do sistema, construída com "organizadores gráficos" para apoiar os alunos na visualização e compreensão do conteúdo, foi avaliada por 42 estudantes de Biologia. Os resultados foram positivos, porém 11 alunos mencionaram dificuldades em localizar conceitos importantes. Em conseqüência, tanto a estrutura como a interface foram modificadas em uma segunda versão, utilizando-se um mapa conceitual (Novak e Gowin, 1984) para a apresentação da interface gráfica. Esta versão foi avaliada por outro grupo de 24 alunos nas mesmas condições que a primeira turma, obtendo-se resultados positivos em relação à organização e orientação dos alunos no uso sistema. Os resultados sugerem que os mapas conceituais contribuem positivamente para a representação do conhecimento de um especialista e também para auxiliar a busca e consulta de informações em sistemas hipermídia.
\end{abstract}

Palavras-chave: hipermídia na educação. desenho instrucional. representação gráfica. Anticorpos Monoclonais.

Abstract: We report the development of the Monoclonal Antibodies Hypermedia System, aimed at Biosciences undergraduate students. The method used for defining the hypermedia structure and the interface was based on the content specialist structural knowledge. The system first version presented a graphic interface based on a "graphic organizer" to support students navigation and comprebention. Forty two Biology students used the bypermedia as part of the Imunology course activities. Although the hypermedia system was positively evaluated by the students., 11 students reported difficulties in finding information in the hypertext structure. Based on results, the system structure and interface were redesigned. The second version was based on "concept map" (Novak. \& Gowin, 1994). This version was evaluated by another group of 24 Biology students, presenting positive findings about their orientation and navigation. The results show that among different multidimentional structures, concept maps are effective for specialist content representation and to support student navigation.

Key words: hypermedia in education. instructional design. graphic representation. Monoclonal Antibodies.

\footnotetext{
Apoio: $\mathrm{CNPq}$

${ }^{1}$ Professora Adjunta, Núcleo de Tecnologia Educacional para a Saúde, Universidade Federal do Rio de Janeiro (NUTES/

UFRJ); Coordenadora, Laboratório de Tecnologias Cognitivas (LTC/NUTES).E-mail:miriamstru@yahoo.com.br

2 Técnica em Assuntos Educacionais, LTC/NUTES/UFRJ.E-mail: regviri@@yahoo.com.br

3 Pesquisadora,LTC/NUTES/UFRJ.E-mail:taisrg@yahoo.com.br
} 


\section{Introdução}

Sistemas hipermídia educacionais são ambientes que possibilitam não apenas a riqueza de disponibilidade de bases de informações audiovisuais mas, também, novas formas de organização do conhecimento. Estruturas não-lineares, como a hipermídia, oferecem ao aluno liberdade de buscar e consultar informações, associando conceitos de acordo com seu nível, necessidade e interesse de aprofundamento no conteúdo. No entanto, esses sistemas ainda não se encontram amplamente difundidos no contexto educacional, e a falta de familiaridade com sua estrutura de conteúdo pode, de certa forma, oferecer algumas dificuldades de orientação aos alunos mais experientes com outros materiais.

Os elementos gráfico-editoriais dos materiais impressos, tais como composição de texto, tipologias diferenciadas hierarquicamente, divisão em capítulos, índice, sumário, notas de pé de página são artefatos visuais familiares utilizados para facilitar a leitura, a orientação e a manipulação da informação. Já os sistemas hipermídia, por sua natureza não linear, adotam outros instrumentos, cuja finalidade é orientar os usuários no processo de busca e consulta, isto é, na "navegação", pelas informações. McKnight, Dillon e Richardson (1993) classificam os "instrumentos de navegação" (menus, índices, mapas de conteúdo, botões etc.) como mediadores dos esquemas mentais dos usuários em relação ao sistema e seus elementos.

O presente trabalho apresenta a evolução do desenvolvimento do sistema hipermídia Anticorpos Monoclonais, dirigido a alunos de graduação na área de ciências biomédicas, que teve como base para a sua definição a estrutura conceitual do professor/especialista em Imunologia. Nosso foco principal é a discussão sobre as implicações desta opção em relação ao nível da concepção do hipermídia, organização do conteúdo e definição da interface, bem como as mudanças realizadas neste sistema com base nos resultados obtidos na experiência-piloto com alunos de graduação em Biologia.

\section{Fundamentação teórica}

"Navegando" em ambientes estruturados não-linearmente, os leitores podem combinar as informações de maneiras diferentes, de acordo com as suas necessidades individuais, gerando vários documentos com estruturas diferenciadas de conhecimento. Isto pode ser uma dificuldade para os alunos e professores, na medida em que se distancia dos modelos convencionais e culturalmente incorporados, que seguem uma organização linear para a busca e obtenção de informações. Vários estudos têm descrito características tanto de interfaces como de estruturas de hipertextos que provocam desorientação e sobrecarga cognitiva nos usuários (Robinson e Kiwera, 1995; Baylor, 2001). Portanto, são importantes as ferramentas de busca e acesso (navegação) à informação que apóiem os estudantes.

Como apontam Chou e Lin (1998), o tipo de ferramenta de navegação a ser utilizado é uma decisão-chave, já que exerce uma influência significativa sobre passos de busca dos estudantes e no desenvolvimento de modelos mentais. Cada ferramenta determina uma forma específica de acesso e oferece ao usuário um modelo cognitivo da estrutura do sistema e de seu conteúdo. Por exemplo, o menu apresenta uma estrutura modular; as setas de 
direção, uma estrutura seqüencial; o mapa de conteúdo, uma estrutura global; os botões (hotword), uma estrutura semântica, e o índice alfabético, cuja estrutura está ausente.

Segundo Robinson et al. (2003), os elementos gráficos editoriais (text adjuncts) diferem em termos de dimensionalidade. Alguns elementos são unidimensionais (sumários, setas de orientação, outlines, dentre outros), uma vez que só podem ser compreendidos de maneira linear, visualizando-se o seu conteúdo em uma única direção. Outros elementos são multidimensionais, não apresentando uma organização linear da informação que veiculam (mapas geográficos, mapas conceituais, organizadores gráficos, ilustrações etc). Na literatura, diversos trabalhos apontam que esses elementos multidimensionais espaciais são mais efetivos em apoiar os estudantes no aprendizado de relações entre conceitos do que os elementos lineares (Macdonald e Stevenson, 1999; Robinson e Kiewra, 1995).

Diferentemente dos artefatos unidimensionais, os multidimensionais caracterizam-se por serem construções diagramáticas, em sua maioria simbólicas, que oferecem uma organização de elementos e conceitos determinada por aqueles que a desenvolvem. Portanto, essas construções diagramáticas envolvem aspectos cognitivos complexos que, em muito, podem influenciar a forma como os usuários interagem com o conteúdo dos sistemas (O’Donnell et al., 2002).

Chandrasekaran et al. (1995) afirmam que é possível referir-se a diagramas "externos" ou "internos", apontando algumas diferenças entre estes dois tipos de representação: diagramas externos são construídos por agentes, utilizando determinado meio do "mundo exterior" (papel, computador etc.) e são compreendidos como expressões das representações internas que estes agentes possuem dos objetos e/ou fenômenos representados; já os diagramas internos, envolvem modelos mentais que podem possuir propriedades figurativas. Ambas as representações possuem papel fundamental no pensamento/raciocínio e na resolução de problemas e, portanto, o termo diagrama pode se referir tanto a modelos mentais (Johnson-Laird, 1983 apud Moreira, 1999) ou a figuras representadas diagramaticamente.

Existe um grande número de atributos visuais que podem ser representados e interpretados em uma dada representação visual (relações de vizinhança/localização, hierarquia, tamanho, intensidade, interseções etc.), e que possibilitam inferências relativamente fáceis e diretas sobre os fenômenos estudados. No entanto, diagramas não apenas auxiliam na elaboração de inferências mais diretas, mas também na seleção de métodos para a resolução de determinados problemas; isto é, os diagramas auxiliam na organização da atividade cognitiva.

No âmbito da psicologia da aprendizagem, conhecimento estrutural é o conhecimento sobre como os conceitos de determinado domínio se inter-relacionam. Jonassen et al. (1993) definem três formas de conhecimento: o conhecimento declarativo diz respeito ao reconhecimento de objetos, eventos ou idéias (saber que); o conhecimento procedural está relacionado às formas de uso e/ou aplicação do conhecimento declarativo (saber como); finalmente, o conhecimento estrutural é aquele que estabelece as inter-relações entre conceitos de um determinado domínio (saber por que). Estes três tipos de conhecimento são integrados e interdependentes, formando um contínuo, onde o conhecimento estrutural é mais abrangente e complexo. Conhecimento estrutural é também denominado estrutura cognitiva.

A abordagem construtivista entende que, quando o conhecimento necessita ser acessado, ele é reconstruído pelo indivíduo; esta visão de uma estrutura cognitiva flexível e dinâmica, porém sólida do ponto de vista da rede conceitual, é fundamental para reafirmar a 
condição da mente e da memória humana não como repositórios de informação, mas como dependentes das estruturas internas que interconectam os conceitos e proposições internalizados e que se reconstroem nas experiências vivenciadas e nos processos de aprendizagem. Esta visão associa a idéia de conhecimento estrutural ou estrutura cognitiva à teoria da aprendizagem significativa de David Ausubel (Ausubel et al., 1978; Ausubel, 2000; Moreira, 1999). Para Ausubel, a principal condição para que ocorra aprendizagem significativa é o estabelecimento de uma relação (ancoragem) do conhecimento novo com o conhecimento prévio, ou seja, sua estrutura cognitiva naquele domínio.

Uma imagem diagramática pode ser compreendida como uma denominação genérica de algumas formas específicas de representação do conhecimento estrutural ou estrutura cognitiva (representional formalism). Serve tanto para acessar e analisar a "estrutura cognitiva de seu autor", como para apresentar informações de forma esquemática, auxiliando na organização do conteúdo dos processos educativos e na sua internalização e compreensão (Jonassen et al., 1993). Em qualquer das situações, a complexidade do diagrama varia com a intencionalidade, o nível de profundidade e o tipo de conhecimento do seu autor.

Existem vários métodos para representar formalmente o conhecimento estrutural num determinado domínio. Os mais compatíveis com a abordagem do presente trabalho são os métodos que guardam relação com a teoria da aprendizagem significativa, tais como os mapas conceituais (Novak, 1998; Moreira e Buchweitz, 1994) e os organizadores gráficos (Robinson et al., 2003).

O conhecimento estrutural do especialista de conteúdo serviu de base para a elaboração da estrutura do sistema sobre Anticorpos Monoclonais e para a decisão de sua representação visual como ferramenta para a busca e consulta de informações. Com base em esclarecimentos e orientações, o professor/especialista construiu uma imagem diagramática sobre Anticorpos Monoclonais.

\section{Metodologia}

O sistema hipermídia Anticorpos Monoclonais foi desenvolvido pelo Laboratório de Tecnologias Cognitivas (Núcleo de Tecnologia Educacional para a Saúde - NUTES/UFRJ) junto com o Laboratório de Imunologia Molecular (Instituto de Biofísica - IBCCF/UFRJ), com o objetivo de contribuir para a melhoria da formação científica dos alunos de graduação da área das ciências biomédicas. Tem, assim, como população-alvo, alunos de cursos de graduação que incluem a imunologia básica como elemento de seu currículo.

O conteúdo do hipermídia pode ser sintetizado da seguinte forma: conceitos básicos de Imunologia associados à temática, contextualização histórica das grandes descobertas no campo da Imunologia e sua relação com a descoberta dos Anticorpos Monoclonais e, finalmente, aplicações e métodos de produção.

\section{Etapas do desenvolvimento}

No período inicial, estabeleceu-se uma dinâmica com a finalidade de integração da equipe de desenvolvimento do sistema, de troca de conhecimen-tos e de construção de uma linguagem comum entre as especialidades envolvidas. Dada a complexidade do tema, definiu- 
se que o professor especialista de conteúdo representaria, de forma diagramática (Novak e Gowin, 1984; Jonassen et al., 1993), a temática dos Anticorpos Monoclonais, para orientar a estrutura básica e auxiliar a delimitação da abrangência do sistema. Esta etapa incluiu, também, decisões de caráter técnico, como o sistema computacional e as ferramentas de autoria a serem utilizadas.

O sistema hipermídia foi estruturado com base em um diagrama do conteúdo, elaborado por um pesquisador/especialista em Anticorpos Monoclonais (Prof. Júlio Scharfstein). Se consideramos que sistemas "hipertextuais" imitam as redes de associação de conceitos, significa que podemos mapear a estrutura do conhecimento de um especialista como estrutura de um hipertexto. Jonassen et al. (1993) advogam, inclusive, que um programa baseado no modelo do especialista pode contribuir para que o aluno reconstrua elementos da estrutura/organização do conteúdo semelhante, o que seria um efeito vantajoso no processo de aprendizagem.

Tomando-se por base o diagrama gerado pelo especialista, desencadeou-se uma série de análises e refinamentos, visando sua maior comunicabilidade com os usuários. O principal desafio foi preservar a natureza, organização e especificidade do conhecimento do especialista, porém adaptando o mapa de forma a atender os requisitos de funcionalidade e usabilidade no que diz respeito ao modelo pedagógico e à interface do sistema. Este processo passou por várias fases de trabalho, que culminaram em duas etapas fundamentais, que classificamos como: Definição da estrutura básica e Definição da apresentação visual. Estas duas fases serão explicitadas a seguir.

Definição da estrutura básica: O diagrama sobre Anticorpos Monoclonais, construído pelo especialista de conteúdo, apresentava uma estrutura complexa e densa de conceitos e de interligações. A análise reviu os elementos redundantes do diagrama do especialista sintetizando-os, agrupando-os e representando suas interligações com os diferentes níveis. Isto resultou em uma organização mais sistemática do diagrama inicial, estabelecendo uma classificação, com os conceitos mais gerais ligados aos mais específicos, em níveis mais baixos. A estrutura final, ainda complexa, foi a base sobre a qual o programa foi construído e guiou a elaboração do texto e dos elementos audiovisuais.

Definição da apresentação visual: para apresentar o conteúdo de forma estruturada, optamos pela elaboração de "organizadores gráficos". Organizador gráfico é um suporte visual que pode estar relacionado a um texto ou a outro tipo de material educativo, tendo como finalidade comunicar a organização do material. Sua apresentação é bem simples, e preserva, sobretudo, a estrutura hierárquica do domínio (árvore). Inicialmente, foi elaborada uma série de organizadores gráficos, os quais passaram por diversas revisões até que o domínio dos Anticorpos Monoclonais terminou representado por seis diagramas que cobrem todo o conteúdo presente no conhecimento estrutural do professor/especialista. O primeiro representa o conteúdo global do modelo científico; ele corresponde à síntese do diagrama inicial do especialista (Figura 1). Cada um dos conceitos do diagrama global foi desenvolvido separadamente, definindo, assim, a geração de subestruturas do sistema. Na Figura 2, pode-se visualizar uma das subestruturas (ramificações) do diagrama inicial. 
Struchiner, M. et al.

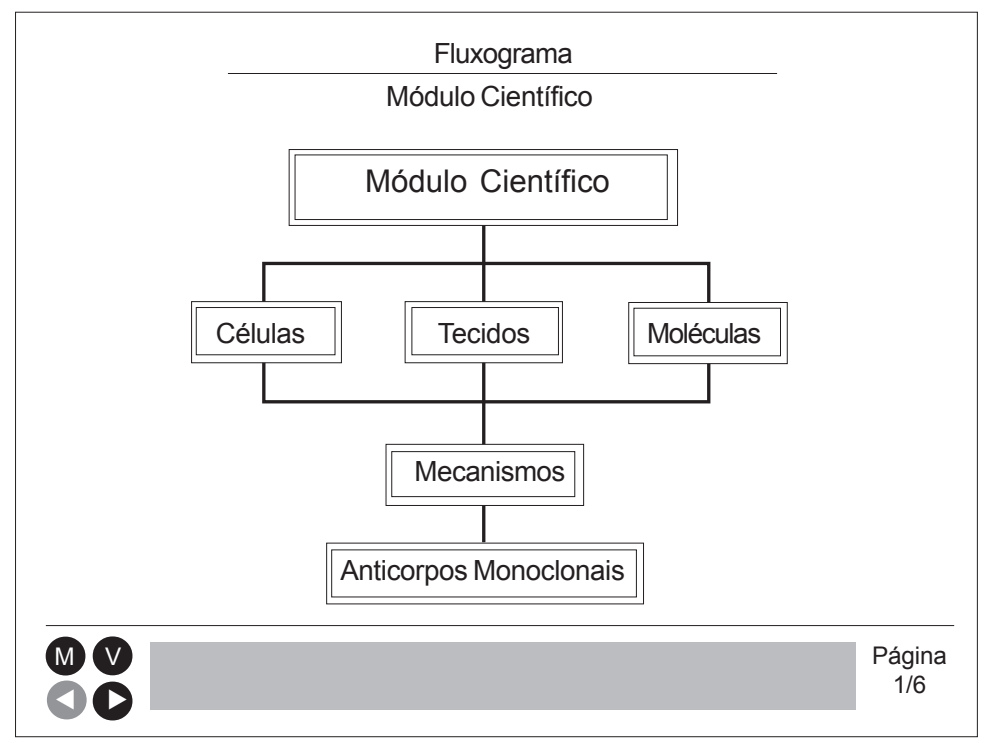

Figura 1. Conteúdo do "Módulo Científico", representado pelo organizador gráfico.

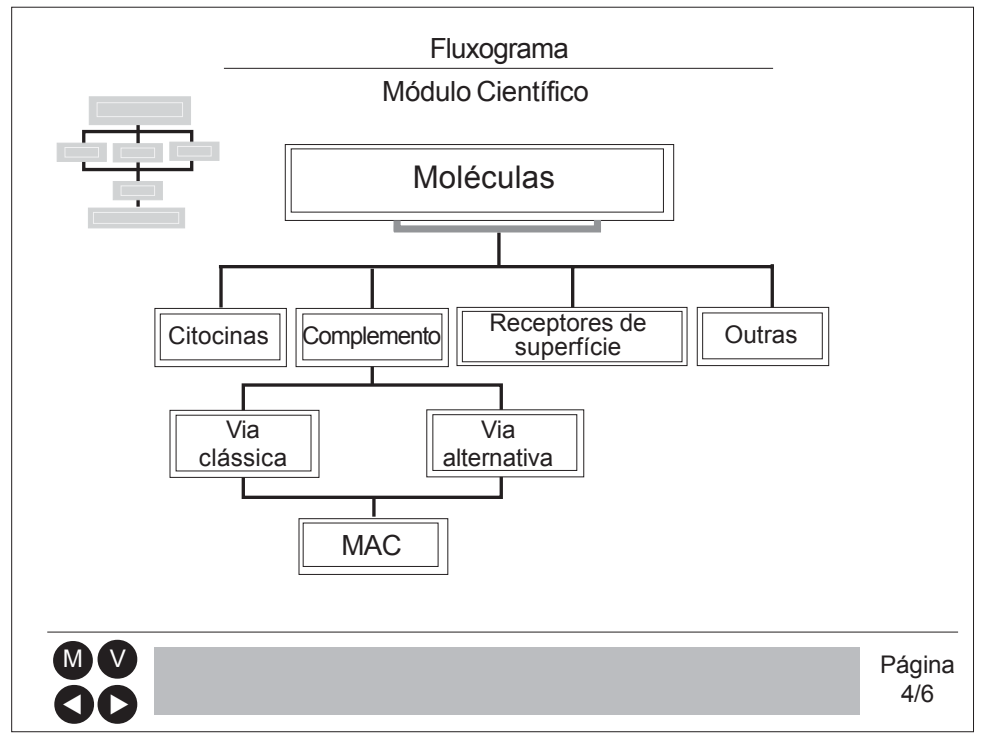

Figura 2. Exemplo de uma das ramificações do organizador gráfico, acionada pelo conceito "moléculas".

Ao entrar no sistema, logo após a abertura (capa), aparece a tela do menu principal com as opções de Introdução, Módulo Histórico, Módulo Científico, Ajuda e Sair. O Módulo Científico possui outras características de funcionamento, uma vez que sua interface cumpre a função de tornar a estrutura conceitual, trabalhada a partir do conhecimento do especialista, 
aparente e manipulável pelo usuário. O aluno depara-se com uma tela contendo o menu em formato gráfico, representando a estrutura global do módulo científico; pode, então, navegar a partir da seleção de qualquer elemento em qualquer nível.

\section{Procedimentos para a avaliação do sistema hipermídia}

Para avaliar o potencial deste meio no ensino da Imunologia e analisar o funcionamento e a interface desta versão do sistema, realizou-se um estudo com alunos do curso de graduação em Biologia/UFRJ ( $\mathrm{N}=42$ ), interagindo com o sistema hipermídia "Anticorpos Monoclonais" durante a disciplina de Imunologia, no Instituto de Microbiologia/UFRJ.

Para estimular a busca de informações dos alunos que utilizaram o software, foi apresentada uma questão abrangente, que foi respondida por escrito após consulta ao sistema, sobre o conceito de anticorpos monoclonais: "O que é, e como éproduzido um anticorpo monoclonal?"

A pesquisa incluiu uma série de procedimentos e instrumentos para analisar o processo de busca e consulta de informações e a aprendizagem dos alunos com base nesses sistemas; para isso, utilizou respectivamente o registro do histórico de navegação do aluno e a elaboração de mapas conceituais sobre o tópico, antes e depois de utilizarem o sistema. Um instrumento de avaliação do software também foi respondido pelos estudantes, após a navegação, com o objetivo de coletar informações sobre o uso do sistema e sugestões para o seu aprimoramento. Além de responderem a uma escala de atitudes sobre diferentes aspectos do software, os alunos responderam a algumas questões abertas: 1. cite três aspectos positivos do sistema hipermídia; 2. cite três aspectos negativos do sistema hipermídia; 3. identifique os pontos que não ficaram claros no programa; e 4. indique as sugestões para melhorar o programa.

\section{Resultados da avaliação dos alunos}

Dos 42 alunos que participaram do estudo, 35 completaram todas as etapas, e os dados relativos às suas respostas foram analisados. No que diz respeito à escala de avaliação, foram apresentadas 15 frases de opinião (afirmativas e negativas) acerca do sistema hipermídia, nos seguintes aspectos: (1) interatividade (três itens); (2) interface (quatro itens); (3) conteúdo (seis itens); (4) programação visual (dois itens).

A média obtida na avaliação do grupo como um todo foi de 114,6 (115), de um total máximo possível de 150 pontos se todos os participantes tivessem dado pontuação máxima a todos os itens. Isto corresponde a um índice de $76,4 \%$ de aceitação em relação a diversos aspectos do programa.

Ao responderem às questões abertas, de um modo geral, assim como na escala de opinião, os alunos avaliaram o programa positivamente, ressaltando aspectos como a liberdade de escolha de caminhos, a inter-relação entre conceitos, clareza do texto, e, sobretudo, o uso de imagens, especialmente as animadas, para a compreensão de conceitos. Entre os aspectos negativos, o comentário mais recorrente foi uma crítica à leitura na tela do computador, extremamente cansativa, e à lentidão dos microcomputadores utilizados para acessar as informações.

Ao serem questionados sobre os aspectos que não ficaram claros no sistema, apesar de 22 alunos (63\%) não terem levantado qualquer aspecto, dos 13 restantes, 11 (85\%) levanta- 
ram a mesma questão, o que levou ao questionamento da organização e estruturação visual do sistema. Este grupo revelou que teve dificuldades para encontrar informações sobre Anticorpos Monoclonais, que é na verdade o foco do sistema e em torno do qual norteou-se a pergunta motivadora para a navegação.

Diante desses resultados, uma análise do diagrama-base do módulo científico e de sua dinâmica levou à constatação de algumas características que poderiam estar contribuindo para uma estrutura confusa que tornava mais difícil para alguns alunos o acesso às informações.

Podemos, assim, sumarizar estas características:

1. visão fragmentada - a apresentação do modelo em diversas telas (não seria possível representar todo o conteúdo pela quantidade de informação/tópicos presente no sistema) levou à representação de um modelo extremamente simplificado e fragmentado do tema Anticorpos Monoclonais, dificultando não apenas sua visão global, como a percepção da interrelação entre os conceitos a eles subordinados e/ou superordenados;

2. leitura hierárquica do diagrama - a organização rígida de uma árvore hierárquica (Bollini e Palma, 2004) pode ter contribuído para dificultar a compreensão do aluno sobre a relação dos conceitos apresentados com a temática dos Anticorpos Monoclonais. Além deste tipo de estrutura não permitir cruzamentos entre níveis e braços da hierarquia, não estabelece a natureza da relação entre os conceitos (Jonassen et al., 1993); e

3. ordenação dos conceitos - além dos pontos levantados acima, a compreensão do diagrama pode ter sido afetada pelo conceito mais abrangente não estar representado diretamente com a temática do sistema hipermídia, mas com a noção de "módulo científico", e uma série de conceitos que seriam necessários à compreensão da descoberta em estudo (pré-requisitos). Esta representação indireta, além de tornar o "caminho" até o foco do sistema mais longo, faz com que o aluno tenha menos liberdade para explorar a temática de acordo com seu interesse e nível de conhecimento, já que este modelo sugere uma seqüência ao material.

Com base nessa análise, concluiu-se que um outro modelo deveria ser experimentado, procurando oferecer algumas soluções aos problemas encontrados. Cabe ressaltar que, mesmo não tendo sido uma questão levantada pela totalidade dos alunos, a dificuldade de encontrar informações de tal relevância no âmbito do sistema hipermídia justificou esta revisão, mesmo sabendo que outras alternativas podem produzir efeitos variáveis.

\section{Reconstrução: um novo modelo baseado em mapa conceitual}

$\mathrm{Na}$ tentativa de explorar caminhos que pudessem oferecer alternativas ao problema de orientação vivenciado pelos estudantes de Biologia, optou-se pela reorganização de parte do material e, especialmente, por uma nova forma de representação visual do conteúdo (diagra$\mathrm{ma}$ ). A finalidade foi optar por caminhos que pudessem levar à resolução dos problemas que o esquema de apresentação da primeira versão levantava: buscou-se, ao mesmo tempo, a simplificação no sentido de tornar os conceitos mais diretos para o aluno e a maior integração entre estes conceitos, possibilitando uma visão mais abrangente do conteúdo e um acesso mais direto ao tema central do sistema hipermídia, ou seja, ao tema dos Anticorpos Monoclonais. Optou-se pela reestruturação do diagrama para um modelo de mapa conceitual (Novak e Gowin, 1984; Novak, 1998). Os mapas conceituais representam, de forma esquemática, as 
relações significativas entre os conceitos, descrevendo visual e verbalmente as correlações entre as idéias de um determinado domínio. É formado por três elementos básicos: balões, linhas e palavras. Os balões representam os conceitos; as linhas definem suas interligações e as palavras indicam os conceitos (nos balões) e a natureza da ligação entre eles (proposições), referentes às linhas. O mapa conceitual é uma estrutura hierárquica, apresentando o conceito mais abrangente na parte superior do gráfico sobre os conceitos subordinados, mais específicos e concretos. Pressupõe, também, o cruzamento (conexões cruzadas) entre conceitos de diferentes níveis e posições na estrutura, mostrando a complexidade e a interconexão de um domínio.

Os mapas conceituais podem ser utilizados para avaliar a aprendizagem, para desenvolver um programa curricular, ou mesmo, para o professor planejar suas atividades de ensino; podem, também, servir para introduzir ou servir de guia para o estudo e para explorar novos materiais (Moreira e Buchweitz, 1994; Novak e Gowin, 1984; Novak, 1998; Novak e Cañas, 2004). Kannkunen (2004) considera a utilização de mapas conceituais um método conscientemente artificial e pragmático de visualizar o pensamento, que pode auxiliar os alunos no processo de raciocínio e no controle da aprendizagem de conceitos.

Desta forma, o mapa conceitual produzido e reavaliado pelo especialista de conteúdo e sua equipe apresentou, como conceito mais abrangente, "Anticorpos Monoclonais" e, como mais específicos, aqueles conceitos mais concretos sobre sistema imune, necessários e "subordinados" à compreensão do modelo de Anticorpos Monoclonais. Decidiu-se pelo desenvolvimento de um mapa conceitual dinâmico, isto é: para o aluno visualizar as palavras de ligação no mapa, basta deslizar o cursor sobre o conceito, que estas aparecem descrevendo a natureza da relação entre os conceitos (figura 3).

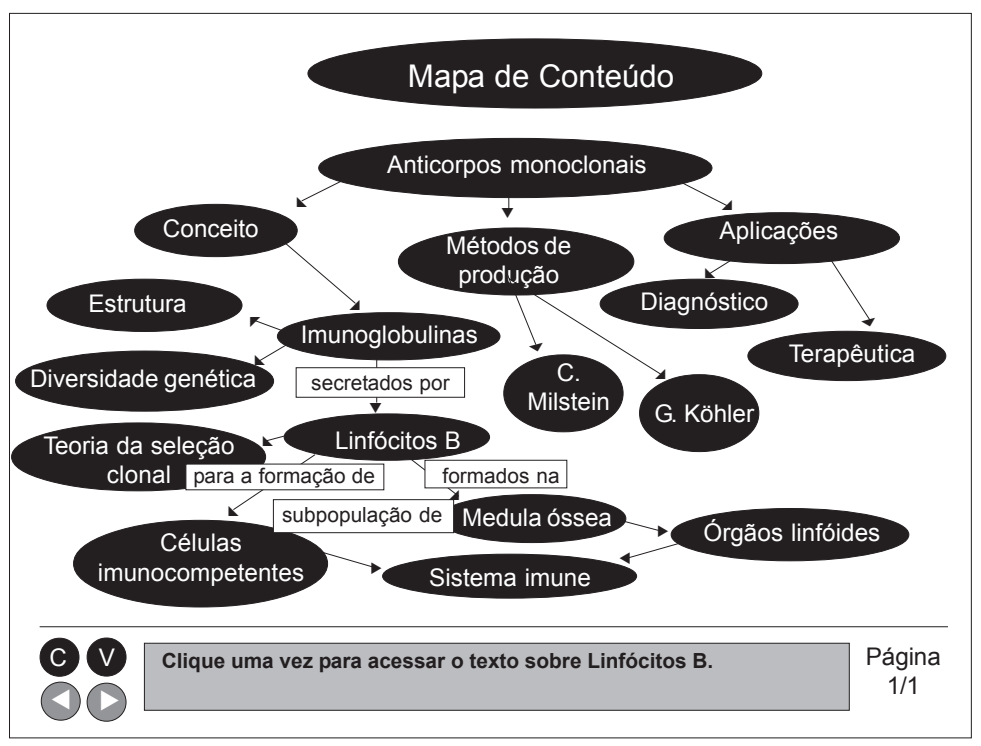

Figura 3. Novo diagrama de conteúdo do sistema, um mapa conceitual. Nesta imagem, o conceito onde o cursor deslizou foi "linfócitos B". 
Struchiner, M. et al.

\section{Avaliação do programa com a nova interface pelos alunos e análise dos resultados}

Valendo-se da nova interface que tem o mapa conceitual como diagrama dinâmico para busca e consulta de informações sobre a temática dos Anticorpos Monoclonais, o mesmo estudo foi replicado, utilizando-se os mesmos procedimentos e instrumentos, com outra turma do curso de Biologia, na disciplina de Imunologia.

Dos 27 alunos que participaram do estudo, 24 completaram todas as etapas, e os dados relativos às suas respostas foram analisados. No que diz respeito à escala de avaliação, foi necessário eliminar uma das questões sobre o uso do módulo de ajuda ao sistema, já que 19 dos 24 alunos não responderam este item, denotando não terem consultado este recurso. A média obtida na avaliação do grupo como um todo foi de 108,8 (109), de um total máximo possível de 140 pontos, se todos os participantes tivessem dado pontuação máxima a todos os itens. Isto corresponde a um índice de $78 \%$ de aceitação em relação a diversos aspectos do programa. Este percentual é bastante semelhante ao primeiro estudo, quando o diagrama de estrutura do programa era um organizador gráfico tradicional.

Ao responderem às questões abertas, de um modo geral, assim como na escala de opiniões, os alunos avaliaram o programa positivamente, ressaltando, tal como no estudo anterior, aspectos que dizem respeito à disponibilidade de recursos de informática no âmbito dos cursos de graduação. Tais comentários incluíram vantagens do sistema sobre Anticorpos Monoclonais, como a disponibilidade de mecanismos variados de acesso às informações e a linguagem de fácil compreensão. $\mathrm{O}$ aspecto criticado mais negativamente foi a dificuldade de manipular a informação contida nas telas, especialmente por conta do excesso de palavraschave que ofereciam diferentes opções de caminhos a serem percorridos dentro do texto no conteúdo do sistema hipermídia.

No entanto, ao serem questionados sobre os aspectos que não ficaram claros no sistema, $11(46 \%)$ alunos não levantaram qualquer aspecto, enquanto que 13 alunos (54\%) levantaram questões e dúvidas a respeito de conceitos trabalhados no conteúdo, e apenas um destes alunos mencionou uma dificuldade em relação à interface, especificamente com os botões de voltar do programa.

\section{Conclusões}

Diante de um cenário em que se busca a melhoria da qualidade da formação científica dos alunos de graduação das ciências biológicas, o desenvolvimento de materiais educativos numa perspectiva construtivista, que contribua para as mudanças necessárias, pressupõe a investigação sobre as relações entre o tipo de organização e representação do conhecimento, o suporte midiático e o processo de aprendizagem (Bolacha e Amador, 2003). Neste contexto, as tecnologias de informação e comunicação (TIC) oferecem recursos que possibilitam novas formas de difusão, acesso e troca de conhecimentos em diferentes formatos (multimídia, hipermídia) veiculados tanto em CD-ROM como pela rede mundial de computadores.

A discussão sobre o processo de construção e reconstrução do sistema Anticorpos Monoclonais, com base nos resultados obtidos com o estudo-piloto, possibilita contribuir para a área de pesquisa e desenvolvimento de materiais educativos informatizados, cuja modela- 
gem baseia-se em princípios do construtivismo, especificamente da aprendizagem significativa. Coloca, também, em evidência a complexa atividade de integração entre: 1 . o conhecimento do especialista de conteúdo, no nosso caso, um professor/pesquisador no campo da imunologia molecular; 2. o desenho instrucional que, ao representar este conhecimento, assume, também, uma série de pressupostos sobre aqueles que serão sujeitos da aprendizagem; e 3. a linguagem do meio a ser utilizado, neste caso, a hipermídia.

Um dos grandes desafios no âmbito da pesquisa e desenvolvimento de sistemas hipermídia é a seleção da melhor forma de representação e organização de seu conteúdo, de maneira a facilitar a navegação e aprendizagem dos alunos, configurando uma importante linha de investigação que pode ser evidenciada em diversos trabalhos existentes na literatura (Bollini e Palma, 2004; Kankkunen, 2004; Robinson e Kiwera, 1995; Odonnel et al., 2002, Macdonald e Stevenson, 1999).

No primeiro estudo, a estrutura de sistema hipermídia estava representada por um organizador gráfico, caracterizado por uma estrutura hierárquica e uma interface modulada de forma relacional para busca de informação. Apesar de 63\% dos alunos não terem levantado qualquer dificuldade, considerou-se importante sua revisão, tendo em vista que 11 (85\%) dos 13 alunos que levantaram algum tipo de problema, se referiam consistentemente à organização e estruturação visual do sistema, que dificultava encontrar conceitos complexos cujos significados dependem da integração de outros subjacentes, como é o caso da temática dos anticorpos monoclonais.

No segundo estudo, já com a estrutura representada pelo mapa conceitual (Novak e Gowin, 1984; Novak, 1998), enquanto 54\% dos alunos levantaram questões e dúvidas a respeito de conceitos trabalhados no conteúdo, apenas um aluno mencionou dificuldade em relação à interface, no que diz respeito à busca de informação. Os alunos da turma que utilizou o sistema com a interface em formato de mapa conceitual ressaltaram a facilidade de navegação e o estímulo à busca de informações; e encontraram suporte facilitado para concentrarem-se nos aspectos complexos do conteúdo da Imunologia, onde a descoberta dos anticorpos monoclonais se insere, e cuja aprendizagem demanda esforço cognitivo de abstração.

Os resultados obtidos com este trabalho apontam para o fato de que, em se tratando de estruturas multidimensionais, os mapas conceituais parecem contribuir positivamente, não apenas para basear a estrutura e a organização de sistemas hipermidiáticos na representação do conhecimento de um especialista, mas também para auxiliar, em nível de interface, os alunos na busca e consulta de informações complexas em sistemas hipermídia.

Estes resultados confirmam uma tendência encontrada nos estudos existentes que procuram investigar a contribuição dos mapas conceituais na organização e apresentação de conteúdos de ensino (Carnot et al., 2001; Reynolds et al., 1991). Em geral, esses estudos enfatizam o potencial do uso dos mapas como uma estratégia para oferecer aos alunos uma visão global e integrada dos diversos conceitos de um determinado domínio do conhecimento. Além disso, demonstram que a aprendizagem de conceitos complexos não pode ser estruturada apenas por meio da informação organizada de modo hierárquico, uma vez que os cruzamentos e as relações entre vários conceitos são aspectos que devem ser destacados (Bolacha e Amador, 2003). Para se obter maior evidência, são necessários outros estudos que avaliem a utilização do mapa conceitual como estratégia de busca e consulta de informações em ambientes hipermídia de aprendizagem de conceitos científicos. 
Struchiner, M. et al.

A utilização dos mapas conceituais não é a única estratégia de organização dos conteúdos em sistemas hipermídia, existindo outras ferramentas potenciais, como os organizadores gráficos (Robinson e Kiewra, 1995) e os mapas de conhecimento (knowledge maps) (O’Donnel et al., 2002). No entanto, os mapas conceituais apresentam características que motivam estudos futuros que explorem seu potencial nos processos de ensino-aprendizagem mediados pelas TICs e, mais especificamente, pela estrutura não-linear da informação da rede mundial de computadores. Isto porque os mapas conceituais possibilitam a representação multimodal da arquitetura informacional, ressaltando as hierarquias, os nós e as conexões conceituais entre os conteúdos de estruturas hipermidiáticas. A interação com a informação se baseia em uma dinâmica de conexões rizomáticas, oferecendo uma representação mais direta do que a usual estrutura de diagrama em árvore. Assim como os mapas geográficos possibilitam a orientação em terras desconhecidas, os mapas conceituais permitem a interpretação, a transmissão e a revisão do conhecimento, da informação e dos dados. A visualização das ligações e cruzamentos entre diferentes conceitos tornam explícitos os caminhos possíveis de construção do conhecimento (Bollini e Palma, 2004).

Desta forma, podemos concluir que os mapas conceituais podem, em muito, favorecer a organização complexa e a visualização de conceitos da área de ensino das ciências biomédicas; e que estes adequam-se à linguagem hipermídia, tanto na estrutura quanto na forma, já que a hipermídia constitui uma rede de conceitos (não-linear) que, por meio dos nós e de suas ligações, realiza todas as possíveis e necessárias conexões e cruzamentos entre conceitos em diferentes níveis de complexidade, necessários à aprendizagem.

Neste trabalho, procuramos descrever as etapas e as soluções implementadas num sistema dirigido a alunos de graduação das áreas biomédicas. Espera-se que as reflexões sobre esta experiência contribuam para trabalhos futuros e de outros grupos no campo da informática educativa.

\section{Referências}

AUSUBEL, D. P. The acquisition and retention of knowledge: a cognitive view. Netherlands: Kluwer Academic Publishers, 2000.

AUSUBEL, D. P.; NOVAK, J. D.; HANESIAN, H. Educational Psychology: a cognitive view. New York: Holt, Rinehart \& Winston, 1978.

BAYLOR, A. Perceived disorientation and incidental learning in a web-based environment: internal and external factors. Journal of Educational Multimedia and Hypermedia, v. 10, n. 3, p. 227-251, 2001. 
Construção e reconstrução de um sistema...

BOLACHA, E.; AMADOR, F. Organização do conhecimento, construção de hiperdocumentos e ensino das Ciências da Terra. Investigações em ensino de Ciências, v. 8, n. 1, 2003. Disponível em: < http://www.if.ufrgs.br/public/ensino/vol8/n1/v8 n1 a2.htm>. Acesso em: 26 abr. 2005.

BOLLINI, L.; PALMA, G. Cognitive maps: new paradigms in information architecture and interface design for the web: the opsis identifier descriptive model for web information architecture based on cognitive maps: designing-X a case study.. In: CAÑAS, A. J.; NOVAK, J. D.; GONZÁLES, F. M. (Eds.). Proceedings of the First International Conference on Concept Mapping. Pamplona, Spain, 2004. Disponível em: < http:// cmc.ihmc.us/papers/cmc2004107.pdf>. Acesso em: 10 abr. 2005.

CARNOT, M.; DUNN, B.; CAÑAS, A. J. Concept map-based vs. web page-based interfaces in search and browsing. Proceedings of the Nineteenth International Conference on Technology and Education. May 2 - 5. Tallahassee, FL, 2001. Disponível em: <http://www.ihmc.us /users/acanas/Publications/CMapsVSWebPagesExp1/CMapsVSWebPagesExp1.htm>. Acesso em: 15 mar. 2005.

CHANDRASEKARAN, B.; GLASGOW, J.; NAYARANAN, N. H. Introduction. In: GLASGOW, B.; CHANDRASEKARAN, B.; NAYARANAN, N. H. (Eds.). Diagrammatic reasoning: cognitive and computational perspectives. Cambridge: MIT Press, 1995. p. xv-xxvii.

CHOU, C.; LIN, H. The effect of navigation map types and cognitive styles on learners' performance in a computer-networked hypertext learning system. Journal of Educational Multimedia and Hypermedia, v. 7, n. 2-3, p. 151-176, 1998.

JONASSEN, D. H.; BEISSNER, K.; YACCI, M. Structural knowledge: techniques for representing, conveying, and acquiring structural knowledge. Hillsdale: Lawrence Erlbaum, 1993.

JONASSEN, D.H.; GRABOWSKY, B. L. Handbook of individual differences, learning and instruction. Hillsdale: Lawrence Erlbaum, 1993.

KANKKUNEN, M. How to acquire "the habit of changing habits": the marriage of Charles Peirce's semiotic paradigm and concept mapping. In: CAÑAS, A. J.; NOVAK, J. D.; GONZÁLES, F. M. (Eds.). Proceedings of the First International Conference on Concept Mapping. Pamplona, Spain, 2004. Disponível em: <http://cmc.ihmc.us/papers/cmc2004-109.pdf> Acesso em: 04 abr. 2005.

MCDONALD, S.; STEVENSON, R. Spatial versus conceptual maps as learning tools in hypertext. Journal of Educational Multimedia and Hypermedia, v. 8, n. 1, p. 43-64, 1999.

MCKNIGHT, C.; DILLON, A.; RICHARDSON, J. Hypertext in context. Cambridge: University Press, 1993. 
Struchiner, M. et al.

MOREIRA, M. A. Aprendizagem significativa. Brasília: Editora Universidade de Brasilia, 1999.

MOREIRA, M.A.; BUCHWEITZ, B. Novas estratégias de ensino-aprendizagem: os mapas conceituais e o vê epistemiológico. Lisboa: Platano Edições Técnicas, 1994.

NOVAK, J. D. Learning, creating, and using knowledge. Mawah: Lawrence Erlbaum, 1998.

NOVAK, J. D.; CAÑAS, A. J. Building on new constructivist ideas and map tools to create a new model for education. In: CAÑAS, A. J.; NOVAK, J. D.; GONZÁLES, F. M. (Eds.). Proceedings of the First International Conference on Concept Mapping. Pamplona, Spain, 2004. Disponível em: < http://cmc.ihmc.us/papers/cmc2004-285.pdf>. Acesso em: 10 abr. 2005.

NOVAK, J. D.; GOWIN, D. Learning how to learn. Cambridge: Cambridge University Press, 1984.

O'DONNEL, A.; DANSEREAU, D.; HALL, R. Knowledge maps as scaffolds for cognitive processing. Educational Psychology Review, v. 14, n. 1, p. 71-86, 2002.

REYNOLDS, S.; PATTERSON, M. E.; SKAGGS, L.; DANSEREAU, D. Knowledge hypermaps and cooperative learning. Computers in Education, v. 16, n. 2, p. 167-173, 1991.

ROBINSON, D. A.; CORLISS, S. B.; BUSH, A. M.; BERA, S. J.; TOMBERLIN, T. Optimal presentation of graphic organizers and text: a case of latge bites? Education Technology Research \& Development, v. 51, n. 4, p. 25-41, 2003.

ROBINSON, D. H.; KIEWRA, K. A. Visual argument: graphic oranizers are superior to outlines in improving learning from text. Journal of Educational Psychology, v. 87, n. 3, p. 455-467, 1995.

Artigo recebido em março de 2006 e aceito em outubro de 2006

Ciência \&̊ Educą̧ão, v. 12, n. 3, p. 247-260, 2006 